\title{
Dermatomyositis: analysis of 109 patients surveyed at the Hospital das Clínicas (HCFMUSP), São Paulo, Brazil*
}

\author{
Luciena Cegatto Martins Ortigosa ${ }^{1}$
}

Vitor Manuel Silva dos Reis ${ }^{1}$

DOI: http://dx.doi.org/10.1590/abd1806-4841.20143422

\begin{abstract}
BACKGROUND: Dermatomyositis affects striated muscles, skin and other organs.
OвJестіVE: To characterize the disease from January 1992 to December 2002, assessing its classification, cutaneous and systemic manifestations, and also laboratory results, therapeutic and prognostic findings compared to those in the literature.

METHODS: Data were obtained from medical records of 109 patients who were classified into five groups: 23 juvenile dermatomyositis; 59 primary idiopathic dermatomyositis; 6 amyopathic dermatomyositis; 7 dermatomyositis associated with neoplasms and 14 dermatomyositis associated with other connective tissue diseases.

RESUlTS: Sixty patients were classified as "definite" diagnosis; 33 as "possible"; four as "probable" and 12 and as amyopathic. The average age at diagnosis was 36 years. Cutaneous manifestations occurred in all patients; the most frequent symptom was loss of proximal muscle strength; the most common pulmonary disorder was interstitial lung disease, and gastritis was the most prevalent digestive manifestation. Tumors were documented in $6.42 \%$ of cases. Lactate dehydrogenase was the muscle enzyme most frequently elevated in the majority of cases. Skin biopsies were performed in 68 patients; muscle biopsies in 53; and electroneuromyographies in 58 patients. The most commonly used treatment was corticotherapy and the mortality rate was $14.7 \%$.

CONCLUSION: in this sample, the disease appeared in younger individuals, was more frequent in women and the association with cancer was small.
\end{abstract}

Keywords: Dermatomyositis; Clinical diagnosis; mortality

\section{INTRODUCTION}

Dermatomyositis (DM) is a connective tissue disease that combines myopathy and distinctive skin manifestations. Etiological aspects including associations with histocompatibility antigens, viruses, drugs and autoimmunity have been considered..$^{1,2}$

The disease affects twice as many women than men and can occur at any age, although it most often appears between 40 and 60 years. The diagnosis of juvenile DM (JDM) usually occurs between five and 14 years of age, without gender predominance and with better prognosis compared to adult patients. ${ }^{2,3}$

Bohan and Peter ${ }^{4}$ published a classification for DM, which was revised in 1996 by Drake et al. ${ }^{5}$ The disease is divided into two categories: without muscle involvement (amyopathic DM or DM without myositis) and with muscle involvement (adult DM - associated or not with cancer -, juvenile DM and overlap syndrome).

Cutaneous manifestations of DM are grouped into pathognomonic (Gottron's papules and Gottron's sign), characteristic (shawl sign, heliotrope, periun- gual telangiectasias and mechanic hands) and compatible (poikiloderma atrophicans vasculare and cutaneous calcinosis) ${ }^{1,3}$ Less common symptoms include facial edema, malignancies, erythrodermia, lichen planus, cutaneous vasculitis and panniculitis; rare manifestations are follicular hyperkeratosis, papular mucinosis, hypertrichosis, malignant erythema, urticaria, urticarial vasculitis, partial lipodystrophy, malignant atrophic papulosis, erythema centrifugum marginatum and vulvar or scrotal involvement. ${ }^{1,2}$

Diagnosis is made through history and physical examination, corroborated by additional tests: muscle enzymes such as aldolase, lactic dehydrogenase (LDH), alanine aminotransferase (ALT), aspartate aminotransferase (AST) and creatine kinase (CK), muscle biopsy, skin biopsy, electroneuromyography, muscle ultrasound and magnetic resonance imaging. ${ }^{2,6}$

The drugs of choice for initiating the treatment are corticosteroids and approximately $25 \%$ of DM patients are resistant to their use. In this case, the asso-

Received on 22.05.2013.

Approved by the Advisory Board and accepted for publication on 22.07.2013.

Work performed at Universidade de São Paulo, at the Hospital das Clínicas (HC-FMUSP) - São Paulo (SP), Brazil.

Financial support: None.

Conflict of interests: None.

Universidade de São Paulo (USP) - São Paulo (SP), Brazil.

(C)2014 by Anais Brasileiros de Dermatologia

An Bras Dermatol. 2014;89(5):719-27. 
ciation of immunosuppressants such as methotrexate, azathioprine, cyclophosphamide, mycophenolate mofetil, chlorambucil, cyclosporine or immunobiological drugs, is required. ${ }^{1,6}$

Prognosis depends on several factors such as, patient's age, severity of myositis, presence of dysphagia, cardiopulmonary involvement and association with neoplasms, early diagnosis and treatment, in addition to patient's response to treatment with corticosteroids. ${ }^{5}$

This study is a clinical-epidemiological study of patients with DM seen at the Dermatology and Rheumatology Services at São Paulo University (USP) Medical School Clinics Hospital.

\section{MATERIALS AND METHODS}

We reviewed the medical records of patients from the Dermatology and Rheumatology Clinics, at São Paulo University (USP) Medical School Clinics Hospital, from January 1992 to December 2002, including in this study 109 patients with the diagnosis of DM confirmed by clinical and laboratory findings.

Medical records were evaluated regarding age at disease onset, gender, race, clinical presentation, cutaneous lesions, association with other systemic diseases and neoplasms, complementary tests, systemic complications and performed treatments.

Only patients with confirmed diagnosis of DM were included in the study, with individuals still under investigation and those in which evolution and laboratory tests pointed to other diseases being excluded from it.

Laboratory tests were considered abnormal above the following values for CK, ALT, AST, LDH and aldolase, respectively: $234 \mathrm{~nm} / \mathrm{ml}, 456 \mathrm{ng} / \mathrm{ml}, 345$ $\mathrm{ng} / \mathrm{ml}, 222 \mathrm{ng} / \mathrm{ml}$ and $333 \mathrm{ng} / \mathrm{ml}$.

We adopted the criteria for diagnosis and classification of DM/PM proposed by Bohan and Peter in 1975, and patients were divided into three groups with possible, probable and definite diagnosis and subsequently classified as juvenile DM (defined as disease start up to 18 years of age), primary idiopathic DM, DM associated with other connective tissue diseases, DM associated with malignancies and amyopathic DM, in which patients had typical manifestations without clinical or laboratory findings of muscle involvement within six months from the detection of cutaneous lesions. ${ }^{4}$ After this distribution, characteristics such as age, gender and race were evaluated for each group.

Once again, patients were separated into two groups: juvenile DM and adult DM, with the description of cutaneous and muscle characteristics, digestive and pulmonary systems disorders, laboratory tests results (muscle enzymes, ANA, anti-jo-1 antibodies) and other complementary tests (anatomopathological examination of cutaneous and muscle lesions, and electroneuromyography). Patients' treatments and outcomes were also described, in addition to the causes of death.

The homogeneity test was used to compare two populations: adult and juvenile DM, regarding the presence of mucin in the dermis during histopathological examination of cutaneous biopsies.

The goals of this study were to demonstrate the characteristics of patients with DM treated in our service and evaluate the laboratory tests ordered by the medical team.

\section{RESULTS}

One hundred and nine medical records of DM patients were reviewed and according to the diagnostic criteria of Bohan and Peter's classification, there were four possible cases $(3.66 \%), 33$ probable cases $(30.27 \%)$ and 72 definite cases $(66.55 \%)$ of the disease (Graph 1).

Eighty-five patients were female $(78 \%)$ and 24 males $(22 \%)$, with a ratio of $3.5: 1$. The minimum age at DM onset was two years old and the maximum was 83 years, with a mean age of 36 years (standard deviation: 19.5 years). The most affected race was Caucasian (white) with 82 patients $(75.2 \%)$; followed by mixed-race (dark-skinned) with 13 patients (12\%); African-American (black), with 12 (11\%), and Asian, with two $(1.8 \%)$.

As shown in table 1, 23 of all cases were classified as juvenile DM (JDM) (21.1\%) and four of these patients $(17.4 \%)$ had only cutaneous symptoms (amyopathic DM - ADM). These cases were considered JDM due to the age at disease onset. This type of DM was more frequent in females, with 18 cases $(78 \%)$ than in males, with five $(22 \%)$ at a ratio of $3.6: 1$. Patients had between two to 18 years (mean age 11 years). Twenty-one patients were white, one darkskinned and one black.

Primary idiopathic dermatomyositis (PIDM) occurred in 59 patients $(54.12 \%)$, with 43 white subjects, eight black, seven dark-skinned and one from Asia. Forty-six cases occurred in females and 13 in

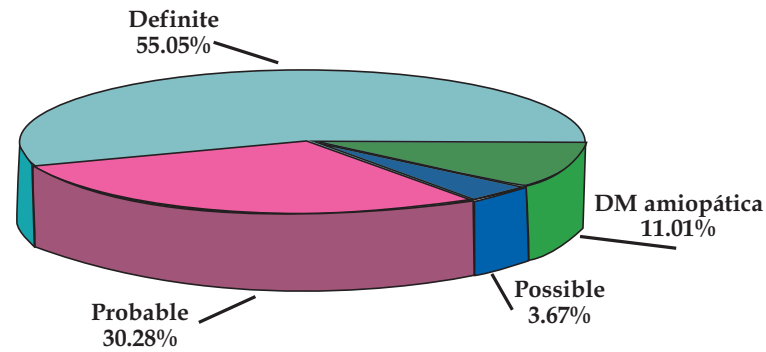

GraPH 1: Distribution of patients diagnosed according to Bohan and Peter criteria, modified by Drake 
males, with ages varying between 20 and 75 years (mean 42 and standard deviation 15 years).

Adult DM was diagnosed in eight patients. One case was associated with connective tissue disease and another with neoplasm. Adding the adult and juvenile ADM, we detected a total of 12 patients (11\%) during the study period. Nine were females (75\%) and three males $(25 \%)$, with ages varying between eight and 73 years (mean age: 32). Eight patients were white, two black and two were dark-skinned.

Association between DM and connective tissue diseases was found in 14 cases $(12.84 \%)$, (Table 2$)$. Amongst them, 12 were women $(85.7 \%)$ and two were men $(14.3 \%)$, aged between 22 and 71 years (mean age: 41). Eight patients were white, three were black and two dark-skinned. The disease most often associated with DM was scleroderma, with seven cases $(50 \%)$, followed by systemic lupus erythematosus (SLE) and Sjögren's syndrome, each with three cases $(21.4 \%)$, and rheumatoid arthritis, with two cases $(14.3 \%)$, (Graph 2). One patient had association of DM, SLE and rheumatoid arthritis.

Neoplasms associated to DM were diagnosed in seven cases $(6.42 \%)$, four female patients $(57 \%)$ and three males $(42.85 \%)$, aged between 31 and 83 years (mean age: 73 years). The most affected ethnic group was Caucasian, with six cases; only one patient was dark-skinned. The identified neoplasms were: nasopharyngeal lymphoepithelioma, tubular adeno- carcinoma of the rectum and cervix, ovarian, gastric, breast and prostate carcinomas. All affected patients died from tumor progression (Table 3).

In the patient sample studied, we found 86 cases of adult DM $(79 \%)$ and 23 cases of JDM $(21 \%)$.

Table 4 describes the cutaneous alterations found in each group. The most common lesion was heliotrope, found in 74 patients $(67.9 \%)$, followed by the Gottron's signal/papules (67\%), photosensitivity $(54.1 \%)$ and poikiloderma $(53.2 \%)$. Raynaud's phenomenon, purpura, hand edema and panniculitis did not occurred in JDM. Cutaneous calcifications were more frequent in JDM (26\%) than in adult DM; among the latter, calcifications occurred in only three individuals $(3.5 \%)$. A case of hypertrichosis was found in a patient with JDM.

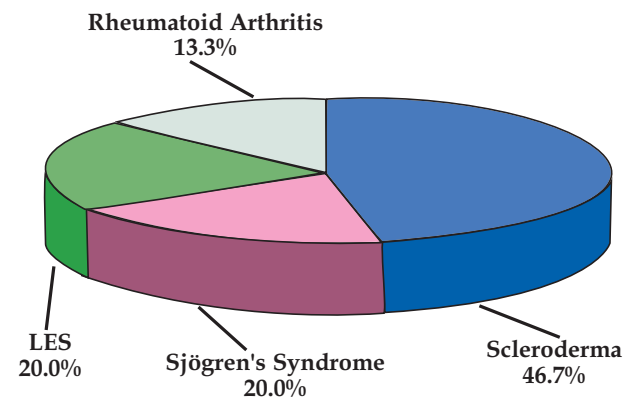

GRAPH 2: Frequency of DM associated with connective tissue diseases

TABle 1: DM by type of diagnosis, according to Bohan and Peter criteria, modified by Drake

\begin{tabular}{llllll}
\hline Classification & \multicolumn{4}{c}{ Type of diagnosis } & TOTAL (\%) \\
\cline { 2 - 5 } & Possible & Probable & Definite & ADM & TOT \\
Juvenile DM & 1 & 11 & 7 & 4 & $23(21.1)$ \\
Primary idiopathic DM & 3 & 13 & 43 & 0 & $59(54.12)$ \\
Neoplasm-associated DM & 0 & 2 & 4 & 1 & $7(6.42)$ \\
DM associated to connective tissue diseases & 0 & 7 & 6 & 1 & $14(12.84)$ \\
Amyopathic DM (ADM) & 0 & 0 & 0 & 6 & $6(5.52)$ \\
\hline TOTAL & $\mathbf{4}$ & $\mathbf{3 3}$ & $\mathbf{6 0}$ & $\mathbf{1 2}$ & $\mathbf{1 0 9}$ \\
\hline
\end{tabular}

TABLE 2: Patients with DM associated to connective tissue diseases

\begin{tabular}{cclll}
\hline Case number & Age (years) & Gender & Race & Type of collagenosis \\
\hline 28 & 22 & Male & White & LES \\
31 & 23 & Female & White & Sjögren's syndrome \\
43 & 27 & Male & Black & RA/LES \\
44 & 28 & Female & Asian & RA \\
46 & 30 & Female & White & Scleroderma \\
48 & 32 & Female & White & Scleroderma \\
52 & 35 & Female & Dark-skinned & Scleroderma \\
62 & 38 & Female & White & Scleroderma \\
83 & 50 & Female & White & Sjögren's syndrome \\
84 & 51 & Female & Dark-skinned & Sjögren's syndrome \\
86 & 54 & Female & White & Scleroderma \\
91 & 56 & Female & White & Scleroderma \\
93 & 59 & Female & Black & LES \\
103 & 71 & Female & Black & Scleroderma \\
\hline
\end{tabular}


Strength loss was the most common muscle symptom observed, occurring in 96 subjects $(88 \%)$, followed by arthralgia (30.2\%), myalgia $(12.8 \%)$ and arthritis $(8.25 \%)$. Muscle contracture occurred in one patient with JDM (Graph 3).

Among the 109 cases, 31 lung abnormalities were observed, the most frequent ones being interstitial lung disease, diagnosed in 19 patients $(17.4 \%)$, and bacterial pneumonia in eight cases $(7.3 \%)$, (Table 5).

Gastrointestinal tract disorders are described in graph 4. Gastritis occurred in 22 patients $(20.2 \%)$ and one case of intestinal vasculitis was diagnosed in a patient with JDM.

Of all muscle enzymes tested, DHL was elevated in the majority of patients $(78.6 \%)$. It was followed by alterations in AST (57.7\%), aldolase (57.35\%), CK $(54.3 \%)$ and ALT (50\%), (Table 6). ANA was requested for 97 patients of which $68(70 \%)$ had a positive test, with 56 cases presenting a speckled pattern $(82.3 \%)$, eight with homogeneous $(11.8 \%)$ and three with nucleolar patterns $(4,4 \%)$ and one case with centromere pattern $(1.5 \%)$. Of the 37 anti-Jo- 1 antibody tests requested, four $(10.8 \%)$ were positive (Table 7$)$.
Sixty-eight skin biopsies with histopathologic examination (62\% of cases) were performed: 53 exams were compatible with DM (78\%) and 27 samples had mucin in the dermis (39.7\%), this feature being most noticeable in JDM, with 10 cases in 16 biopsies $(62.5 \%)$. Muscle biopsies were requested for 53 patients (48.6\% of cases), with results consistent with $\mathrm{DM}$ in 51 cases $(96 \%)$. Of the 58 electroneuromyographies (EMG) performed (53\%), 47 (81\%) had typical DM abnormalities (Table 8).

Table 9 details the use of corticosteroids in 102 patients $(93.5 \%)$ and chloroquine in 55 individuals (50.4\%), with methotrexate being the most widely used immunosuppressive agent (37 patients - 34\%).

Eighty-nine patients evolved with clinical improvement $(81.6 \%)$, four were cured when discharged $(3.67 \%)$ and 16 died $(14.7 \%)$, (Graph 5). Two deaths occurred in JDM patients $(8.7 \%)$, caused by gastrointestinal bleeding and pneumonia, and 14 in adult patients with DM $(16.3 \%)$, seven deaths were caused by internal neoplasms, three by pneumonia, three by septicemia and one by tuberculosis (Graph 6).

TABLE 3: Patients with DM associated with neoplasms

\begin{tabular}{cclll}
\hline Case number & Age (years) & Gender & Race & Neoplasm \\
\hline 47 & 31 & Female & White & Nasopharyngeal lymphoepithelioma \\
77 & 47 & Male & White & Rectal Adenocarcinoma \\
98 & 63 & Female & White & Cervix Carcinoma \\
102 & 68 & Female & White & Ovarian Carcinoma \\
106 & 73 & Male & White & Prostate Carcinoma \\
107 & 74 & Male & White & Gastric Carcinoma \\
109 & 83 & Female & Dark-skinned & Breast Cancer \\
\hline
\end{tabular}

TABLE 4: Distribution of cutaneous alterations according to age ran

\begin{tabular}{llll}
\hline Cutaneous alterations & \multicolumn{2}{c}{ Age range } & \\
\cline { 2 - 3 } & 0-19 & $\mathbf{2 0 - 8 9}$ & Total (\%) \\
& years & years & \\
\hline Heliotrope & 15 & 59 & $74(67.89)$ \\
Gottron's & 15 & 58 & $73(66.97)$ \\
Poikiloderma & 12 & 46 & $58(53.21)$ \\
Photosensitivity & 10 & 49 & $59(54.13)$ \\
Raynaud's phenomenon & 0 & 15 & $15(13.76)$ \\
Malar rush & 4 & 14 & $18(16.51)$ \\
Fingertips' vasculitis & 2 & 11 & $13(11.92)$ \\
Periungual telangiectasias & 8 & 29 & $37(33.94)$ \\
Hair thinning & 4 & 28 & $32(29.36)$ \\
Livedo reticularis & 2 & 4 & $6(5.5)$ \\
Erythroderma & 1 & 5 & $6(5.5)$ \\
Cutaneous ulcers & 2 & 13 & $15(13.76)$ \\
Oral aphthae & 1 & 9 & $10(9.17)$ \\
Purpura & 0 & 3 & $3(2.75)$ \\
Xerosis cutis & 1 & 8 & $9(8.25)$ \\
Hand edema & 0 & 4 & $4(3.67)$ \\
Panniculitis & 0 & 3 & $3(2.75)$ \\
Scalp desquamation & 3 & 4 & $7(6.42)$ \\
Cutaneous calcification & 6 & 3 & $9(8.25)$ \\
Hypertrichosis & 1 & 0 & $1(0.91)$ \\
& & & \\
\hline
\end{tabular}

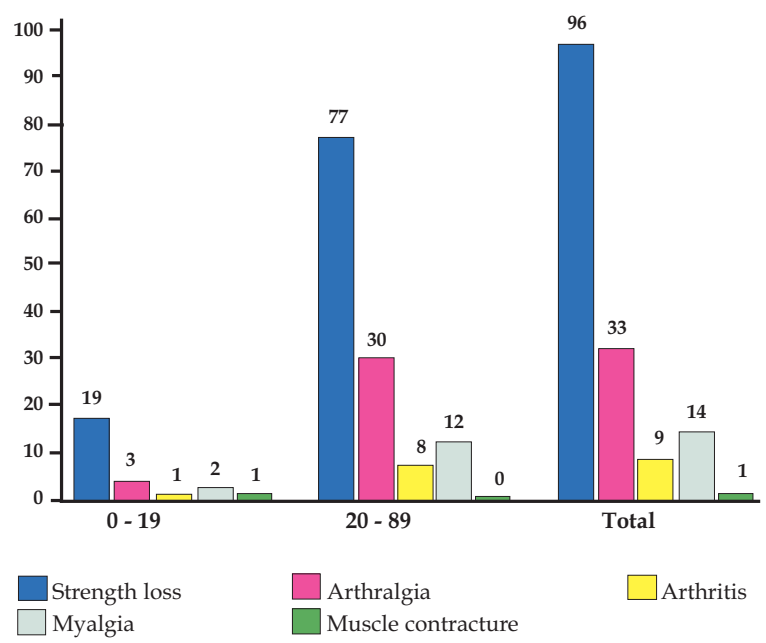


TABLE 5: Pulmonary disorders associated with DM according to age range

\begin{tabular}{|c|c|c|c|c|c|c|}
\hline \multicolumn{7}{|l|}{ Pulmonary disorders } \\
\hline & \multicolumn{2}{|c|}{$0-19$ years } & \multicolumn{2}{|c|}{$20-89$ years } & \multicolumn{2}{|l|}{ Total } \\
\hline & Patients & $\%$ & Patients & $\%$ & Patients & $\%$ \\
\hline Interstitial pneumonitis & 1 & 0.91 & 17 & 15.59 & 18 & 16.5 \\
\hline Bacterial pneumonia & 1 & 0.91 & 7 & 6.42 & 8 & 7.33 \\
\hline Tuberculosis & 0 & 0 & 3 & 2.75 & 3 & 2.75 \\
\hline Pulmonary metastases & 0 & 0 & 1 & 0.91 & 1 & 0.91 \\
\hline TOTAL & 2 & 1.82 & 28 & 25.7 & 30 & 27.52 \\
\hline
\end{tabular}

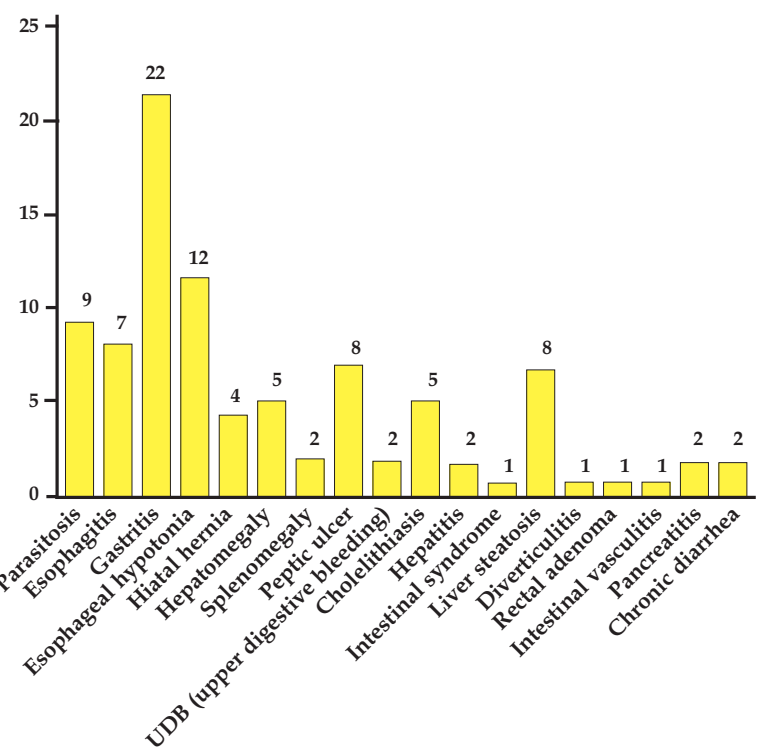

GRAPH 4: DM-associated gastrointestinal tract abnormalities presented by the patients

TABLE 6: Distribution of cutaneous alterations according to age ran

\begin{tabular}{lllll}
\hline EXAME & & \multicolumn{3}{c}{ Age range } \\
\cline { 3 - 5 } & & $\mathbf{0 - 1 9}$ & $\mathbf{2 0 - 8 9}$ & Total \\
& & years & years & \\
\hline AST & Not performed & 3 & 2 & 5 \\
& Altered & 10 & 50 & 60 \\
& Normal & 10 & 34 & 44 \\
ALT & Not performed & 3 & 2 & 5 \\
& Altered & 9 & 43 & 52 \\
& Normal & 11 & 41 & 52 \\
CPK & Not performed & 2 & 1 & 3 \\
& Altered & 11 & 46 & 57 \\
& Normal & 10 & 38 & 48 \\
LDH & Not performed & 2 & 4 & 6 \\
& Altered & 17 & 64 & 81 \\
Aldolase & Normal & 4 & 18 & 22 \\
& Not performed & 9 & 32 & 41 \\
& Altered & 11 & 28 & 39 \\
ANA & Normal & 3 & 26 & 29 \\
& Not performed & 4 & 8 & 12 \\
& Altered & 13 & 55 & 68 \\
JO - 1 & Normal & 6 & 23 & 29 \\
& Not performed & 17 & 55 & 72 \\
& Altered & 0 & 4 & 4 \\
& Normal & 6 & 27 & 33 \\
& & & &
\end{tabular}

TABLE 7: ANA patterns

\begin{tabular}{lllll}
\hline \multicolumn{5}{c}{ PATTERN } \\
\hline Speckled & Homogenous & Nucleolar & Centromere & Total \\
\hline $56(82.3 \%)$ & $8(11.8 \%)$ & $3(4.4 \%)$ & $1(1.5 \%)$ & 68 \\
\hline
\end{tabular}

\section{DISCUSSION}

The diagnostic criteria, proposed by Bohan and Peter ${ }^{4}$, were used in this series in order to have a homogeneous group, with precise inclusion and exclusion methods and correct validation of the data obtained. Some studies evaluate patients with dubious diagnosis; several have the majority of cases classified as possible and not definite diagnosis. Reports regarded as important in the literature present the majority of DM cases as definite and probable, such as Bohan et al, with $98.7 \%$ of definite and probable cases; Tymms and Webb, with $73.3 \%$; and Koh et al., with $82.9 \%{ }^{7.8,9}$ The current study is relevant, because of the 109 patients, $105(96.8 \%)$ had definite and probable diagnosis.

Females were the most affected ones ( $p$ $<0.0001$ ), similarly to other retrieved studies. ${ }^{710-17}$ The group of patients with dermatomyositis associated with neoplasms (NDM) had equal proportions of men and women, but in all other groups, females were more affected.

The average age at disease onset was 36 years, demonstrating the occurrence of DM in young individuals and drawing attention to the need of further and larger studies, regarding the genetic and environmental factors that favor an earlier onset of the disease in this country, since in other reviewed studies, it occurred most often between 45 and 65 years of age..$^{18,19}$

Patients with PIDM were the most frequently observed ones, in consonance with the works of Benbassat et al. and Parodi et al..$^{20,21}$

Several authors studied JDM and their data are similar to these, except for the study by Chowdhary et al., which demonstrated predominance of males over females, possibly due to the small sample size (12 boys and seven girls). ${ }^{15,22-29}$

Diagnostic criteria for ADM vary depending on the study analyzed and disease prognosis is unclear. El-Azhary and Pakzad found 37 ADM cases among $746 \mathrm{DM}$ patients (5\% of the sample). ${ }^{30}$ Twenty-eight 
TABLE 8: Distribution of complementary exams per age range

\begin{tabular}{|c|c|c|c|c|c|c|c|c|}
\hline \multirow[t]{3}{*}{ EXAMS } & & & \multicolumn{6}{|c|}{ AGE RANGE } \\
\hline & & & \multirow{2}{*}{\multicolumn{2}{|c|}{$\begin{array}{l}0-19 \\
\text { YEARS }\end{array}$}} & \multirow[t]{2}{*}{$20-89$} & & \multirow{2}{*}{\multicolumn{2}{|c|}{ TOTAL }} \\
\hline & & & & & & YEARS & & \\
\hline & & & $\mathbf{N}^{\mathbf{o}}$ & $\%$ & $\mathbf{N}^{\mathbf{o}}$ & $\%$ & $\mathbf{N}^{\mathbf{o}}$ & $\%$ \\
\hline \multirow[t]{3}{*}{ SKIN BIOPSY } & Not performed & & 7 & 6.42 & 34 & 31.20 & 41 & 37.62 \\
\hline & Performed & $\begin{array}{l}\text { Compatible with DM } \\
\text { (Presence of mucin) }\end{array}$ & $14(10)$ & $12.84(9.17)$ & $39(17)$ & $35.78(15.6)$ & $53(27)$ & $48.62(24.77)$ \\
\hline & & Normal & 2 & 1.83 & 13 & 11.93 & 15 & 13.76 \\
\hline \multirow[t]{3}{*}{ MUSCLE BIOPSY } & Not performed & & 16 & 15.6 & 39 & 35.78 & 56 & 51.38 \\
\hline & Performed & Compatible with myositis & 6 & 5.5 & 45 & 41.25 & 51 & 46.79 \\
\hline & & Normal & 1 & 0.915 & 1 & 0.915 & 2 & 1.83 \\
\hline \multirow[t]{3}{*}{ ENMG } & Not performed & & 16 & 14.68 & 35 & 32.11 & 51 & 46.79 \\
\hline & Performed & Compatible with DM & 5 & 4.59 & 42 & 38.53 & 47 & 43.12 \\
\hline & & Normal & 2 & 1.83 & 9 & 8.26 & 11 & 10.09 \\
\hline
\end{tabular}

TABLE 9: Treatment assessment of 109 cases of dermatomyositis

\begin{tabular}{|c|c|c|c|c|c|c|}
\hline \multirow[t]{2}{*}{ TREATMENT } & \multicolumn{6}{|c|}{ AGE RANGE (YEARS) } \\
\hline & $0-19$ & $\%$ & $20-89$ & $\%$ & TOTAL & $\%$ \\
\hline Oral corticoid & 20 & 18.35 & 82 & 75.23 & 102 & 93.58 \\
\hline Chloroquine & 11 & 10.09 & 44 & 40.37 & 55 & 50.46 \\
\hline Methotrexate & 6 & 5.50 & 31 & 28.44 & 37 & 33.94 \\
\hline Azathioprine & 6 & 5.50 & 27 & 24.78 & 33 & 30.28 \\
\hline Cyclophosphamide & 0 & 0 & 11 & 10.09 & 11 & 10.09 \\
\hline Cyclosporine & 3 & 2.75 & 19 & 17.43 & 22 & 20.18 \\
\hline Colchicine & 5 & 4.59 & 2 & 1.83 & 7 & 6.42 \\
\hline Methylprednisolone pulse therapy & 3 & 2.75 & 9 & 8.26 & 12 & 11.01 \\
\hline Thalidomide & 1 & 0.92 & 2 & 1.83 & 3 & 2.75 \\
\hline Chlorambucil & 0 & 0 & 4 & 3.67 & 4 & 3.67 \\
\hline Gammaglobulin & 1 & 0.92 & 2 & 1.83 & 3 & 2.75 \\
\hline Mycophenolate mofetil & 0 & 0 & 1 & 0.92 & 1 & 0.92 \\
\hline
\end{tabular}
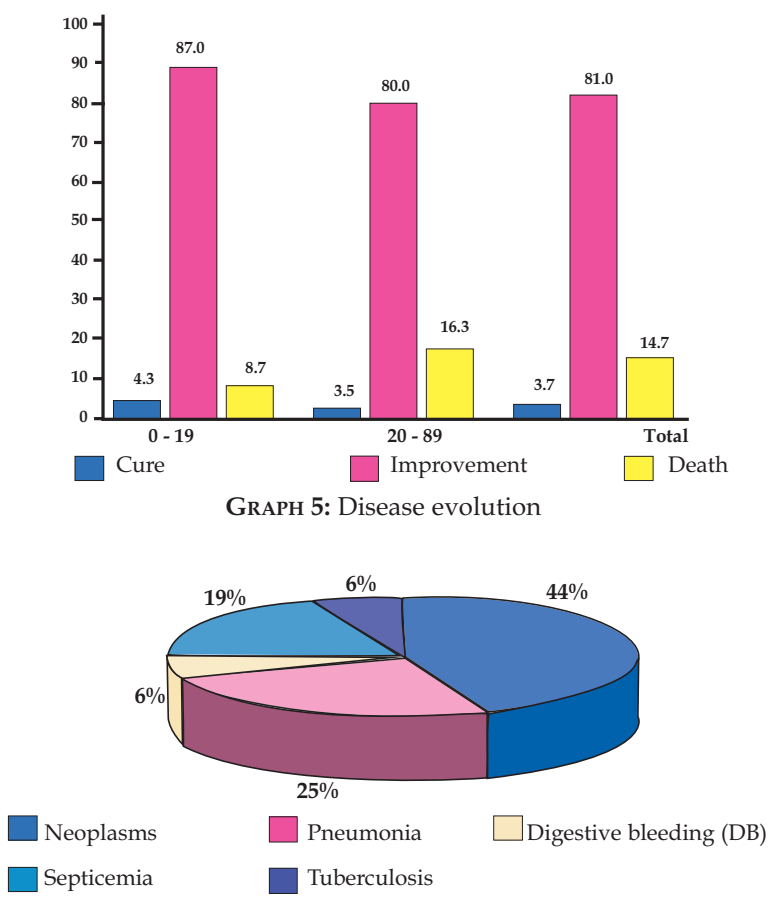

GrAPH 6: Dermatomyositis and causes of death patients were males and nine were females (3:1). Five patients $(13 \%)$ presented associated malignancy. Thirteen of the 157 patients with DM evaluated by Caproni et al. had ADM (8.2\%). ${ }^{31}$ Twelve of them were females and only one was male, with nine cases presenting associated cancer. Cosnes et al. evaluated 63 patients with DM and found 12 ADM cases. ${ }^{32}$ Ten of those were adults and one was a child; one association with malignancy was diagnosed and there was a predominance of females, with 11 cases. In this study, four of 12 patients were younger than 18 years, one had a coexisting connective tissue disease and another had concomitant prostate carcinoma; female gender was more frequent with nine cases detected. In this sample, ADM was slightly associated with neoplasms.

Dermatomyositis associated with connective tissue disease (CDDM) occurred in $12.84 \%$ of the cases, contrasting only with the study by Tymms and Webb, in which 43 of 105 patients had other concomitant connective tissue diseases (41\%). ${ }^{8}$ Scleroderma was the connective tissue disease most frequently associated with DM, ratifying the findings of Trueb, with a prevalence of females, representing $85.76 \%$ of the cases, similar to all reviewed studies. ${ }^{33}$ 
Large works describe the incidence of DM with coexisting neoplasms as varying between 6 and $60 \%$ of cases, with an average of 15 to $30 \% \cdot{ }^{34-36}$ Not all authors, however, recognize this association. Overall, any study that attempts to analyze the link between $\mathrm{DM}$ and cancer faces the problem of DM's low frequency, which causes most reviews to be based on retrospective studies, with all the implicit limitations, whilst prospective series lack sufficient cases to provide statistically significant results.

There are conflicting factors in this classification, such as: a more frequent association of DM and neoplasm after age 60 , malignant tumors induced by the therapeutic use of immunosuppressive drugs and the fact that more tests are conducted to rule out the disease in patients within this age range ${ }^{37}$ We should keep in mind the proper timing and manner of scanning for neoplasms, both in clinical and economic terms.

A large study performed in Europe evidenced a strong association between DM and increased risk of cancer. The authors found 618 patients with DM, 198 of which developed cancer after the diagnosis. ${ }^{36}$ In Australia, the study on malignancy incidence in inflammatory myopathies found that DM was the one with the strongest association. ${ }^{38}$ The link between DM and cancer found in this study was small, compared to other published results. ${ }^{17,20,3947}$

A study conducted in Brazil by Scola et al. ${ }^{13}$ found only four cases of neoplasm in 59 patients with DM $(6.8 \%)$ and the current study detected seven cancer cases in 109 patients $(6.42 \%)$. Of all the patients with NDM, four were women and three were men, unlike other DM groups, in which female rates far exceeded the male ones, however, the statistical analysis of these data was not significant. This may corroborate the works by Basset-Seguin et al. ${ }^{48}$ and Gallais et $a l .{ }^{40}$, in which the authors suggest the male gender as a risk factor for the association of DM with cancer. Nonetheless, Wataka et al. indicated the female gender as a risk factor for the development of neoplasms. ${ }^{49}$

The highest incidence of NDM occurred after the age of 60, comprising five of the seven cases reported $(71.4 \%)$, confirming the findings by Wong, Marie et al. and Staves et al., among others. ${ }^{50-52}$ One case of nasopharyngeal cancer, an association commonly reported in Asian patients, was diagnosed. ${ }^{16,53-55}$ In the work conducted by Basset-Seguin et al., there was $100 \%$ mortality in this group and the same occurred in our study. ${ }^{48}$

Regarding cutaneous alterations, both in JDM as in adult DM, we found a higher frequency of classical signs of the disease, such as: heliotrope, Gottron's papules/sign, poikiloderma and photosensitivity. We cannot, however, disregard other very common nonspecific alterations in DM, such as thin- ning hair in adults and scalp desquamation in children, which occurred in 39 patients in this sample. ${ }^{25}$ Cutaneous calcifications were found more frequently in JDM ( $26 \%$ of cases) compared to adult DM ( $\mathrm{p}=$ 0.002), corroborating the findings of Pachman et al. ${ }^{23}$, which recorded a calcification rate of $23 \%$ in JDM, and Sang-Jun et al., with $37.5 \%$ of cases. Skin lesions were present in $100 \%$ of the assessed patients. ${ }^{15}$

The most common muscle alteration was strength loss, occurring in $88 \%$ of the cases. Most reviewed studies describe a higher percentage of myalgia in relation to arthralgia, as exemplified by Maugers et al., with myalgia's incidence of $59.4 \%$ and arthralgia's rate of $46.4 \% .{ }^{11} \mathrm{~A}$ peculiar fact is that, in the present study, arthralgia was the most common complaint, occurring in $30.2 \%$ in adult DM and $12.8 \%$ of the cases in JDM in consonance with the results reported by Hochberg et al..$^{56}$ and Pinto et al. ${ }^{46}$ which reported $29 \%$ and $62 \%$ of arthralgia rates in patients, respectively.

In general, the association between DM and interstitial lung disease occurs in about $5-30 \%$ of the cases reported in the literature, initially with flu-like symptoms, fever, and later with dyspnea. ${ }^{57}$ Chest radiography and computed tomography show irregular and linear opacities bilaterally, with involvement of lung bases and occasional consolidations in the affected sites. A study performed in Minnesota with 973 patients presenting DM/PM demonstrated the association with interstitial lung disease in 70 of them; in Germany, 63 patients were evaluated, 20 of which $(32 \%)$ developed interstitial lung disease and Schiopu et al. found 16 such cases among 83 patients. ${ }^{17,57,58}$ In this service, computed tomography is requested only when the patient presents pulmonary symptoms or alterations during clinical examination. The most frequent pulmonary disorder was interstitial lung disease, affecting 18 patients (16.5\%), followed by bacterial pneumonia, with eight cases $(7.3 \%)$, which was the cause of death of four patients.

Likewise, endoscopy was only requested for those presenting digestive symptoms. Gastritis was the gastrointestinal tract disorder that occurred more frequently $(20.2 \%)$, probably secondary to the use of corticosteroids, used in most cases in our service to control the disease. Esophageal hypotonia was diagnosed in 12 patients, but it did not occur in patients with JDM. Intestinal parasitosis, common in our midst, was diagnosed in nine cases, and early detection and appropriate treatment are important to prevent major complications during immunosuppressive therapy.

Previous studies reported CK and aldolase as the serum enzymes most sensitive for DM diagnosis; our results revealed the importance of not only these two enzymes, but also of $\mathrm{LDH}$, which was elevated in $78.6 \%$ of the evaluated cases. ${ }^{7,9}$ It is known, however, 
that this is not a specific enzyme and perhaps CK results were not further elevated because some patients were already receiving treatment when they arrived at our service.

Positivity for anti-nuclear antigen (ANA) was $70 \%$, with $61.8 \%$ of positive tests presenting titers above $1 / 160$ ( $p=0.003)$, with "speckled" as the most commonly found pattern (82.3\%). In studies such as those by Bohan et al. ${ }^{7}$, Benbassat et al..$^{20}$ and Maugars et al. ${ }^{11}$, ANA was positive, in $2 \%, 23.6 \%$ and $18.9 \%$ of the cases respectively, but higher positive rates were detected by Tymms and Webb ${ }^{8}$, Koh et al. ${ }^{9}$, and Weitoft ${ }^{59}$, with $52 \%, 47.3 \%$ and $52.6 \%$ respectively. More recent publications demonstrate positivity for ANA in the majority of patients, which was confirmed by the current study.,50 This result shows the importance of ANA as a screening test for the disease, and that high titers may occur in most cases, especially when DM is associated with another connective tissue disease.

Anatomopathological exam of the skin is considered important, especially when other differential diagnoses regarding cutaneous alterations, such as contact dermatitis, seborrheic dermatitis and psoriasis, are suspected. It is a crucial exam, in dermatology, to make the differential diagnoses of poikilodermas, especially to exclude lymphomas. The test is technically easy to perform, barely painful and often without complications. Those are probably the reasons why, in our service, skin biopsies were more frequently requested than muscle biopsies and ENMG, performed respectively in $62 \%, 48.6 \%$ and $53 \%$ of the cases. Sixty-eight skin biopsies were performed, 78\% of which had alterations compatible with DM at the anatomopathological examination. Presence of mucin in the dermis occurred mainly in JDM when compared to adult DM ( $p=0.003)$, a feature that was not reported in the reviewed literature.

Muscle biopsies were performed in 53 patients; a highly sensitive test, it had characteristic DM

\section{REFERENCES}

1. Kimball AB, Summers RM, Turner M, Dugan EM, Hicks J, Miller FW, Rider LG, et al. Magnetic resonance imaging detection of occult skin and subcutaneous abnormalities in juveniledermatomyositis. Implications for diagnosis and therapy. Arthritis Rheum. 2000;43:1866-73.

2. Koler RA, Montemarano A. Dermatomyositis. Am Fam Physician. 2001;64:1565-72.

3. Ortigosa LCM, Romiti R. Dermatomiosite. In: Belda JW, Chiacchio ND, Criado PR. Tratado de Dermatologia. São Paulo: Atheneu; 2000. p.735-54.

4. Boham A, Peter JB. Polymyositis and dermatomyositis (first of two parts). N Engl J Med. 1975;292:344-7.

5. Drake LA, Dinehart SM, Farmer ER, Goltz RW, Graham GF, Hordinsky MK, et al. Guidelines of care for dermatomyositis. American Academy of Dermatology. J Am Acad Dermatol. 1996:34:824-9

6. Callen JP. Dermatomyositis: diagnosis, evaluation and management. Minerva Med. 2002:93:157-67.

7. Bohan A, Peter JB, Bowman RL, Pearson CM. A computer-assisted analysis of 153 patients with polymyositis and dermatomyositis. Medicine (Baltimore). 1977;56:255-86.

8. Tymms KE, Webb J. Dermatopolymyositis and others connective tissue diseases: a review of 105 cases. J Rheumatol. 1985;12:1140-8. changes in $96 \%$ of the cases. This exam is considered the "gold standard" for the diagnosis of myositis, however, due to the invasive aspect of this procedure, few patients were submitted to it. Fifty-eight patients underwent ENMG, $81 \%$ of which had alterations that were compatible with the disease.

As with all reviewed studies, the treatment drug of choice for most cases was oral corticosteroid (prednisone). This drug was combined with antimalarials (chloroquine) in $50.4 \%$ of patients in order to improve cutaneous lesions. Methotrexate (MTX) was prescribed in $34 \%$ and azathioprine in $30.3 \%$ of the cases. MTX is the most widely used immunosuppressant for the treatment of corticoid-resistant DM in the literature ${ }^{33,56,60}$ In this study, the similar use of MTX and azathioprine was demonstrated.

Sixteen deaths $(14.7 \%)$ were reported in this series of 109 patients, a rate comparable to the ones described by Bohan et al. ${ }^{7}$, Koh et al. ${ }^{9}$ and Marie et al. ${ }^{61}$, but unlike other works, in which they reach around 40 and $50 \%{ }^{11,20}$ There was a higher mortality rate amongst adults $(16.3 \%)$, compared to patients with JDM $(8.7 \%)$, thus showing the influence of age on the development of DM. . $^{51,61}$ The most frequent causes of death coincide with those described in the literature, with the main causes in this sample being the progression of neoplasms associated to DM $(44 \%)$ and bacterial pneumonia $(25 \%){ }^{7,9,11,20,48,61}$

\section{CONCLUSION}

Even nowadays, DM still represents a challenge for clinicians, regarding both diagnosis and treatment. In this study, we sought to establish clinical, laboratory and therapeutic criteria based on the analysis of 109 cases followed in this service during a period of ten years. The studied disease is particularly important for dermatologists, because cutaneous alterations often precede muscle symptoms and, in most cases these professionals make the diagnosis. ${ }^{62} \square$

9. Koh ET, Seow A, Ong B, Ratnagopal P, Tjia H, Chng HH. Adult onset polymyositis/dermatomyositis: clinical and laboratory features and treatment response in 75 patients. Ann Rheum Dis. 1993:52:857-61.

10. Oddis CV, Conte CG, Steen VD, Medsger TA Jr. Incidence of polymyositis-dermatomyositis: a 20 years study of hospital diagnosed cases in Allegheny County, PA 1963-1982. J Rheumatol. 1990:17:1329-34.

11. Maugars YM, Berthelot JM, Abbas AA, Mussini JM, Nguyen JM, Prost AM. Long-term prognosis of 69 patients with dermatomyositis or polymyositis. Clin Exp Rheumatol. 1996;14:263-74.

12. Dawkins MA, Jorizzo JL, Walker FO, Albertson D, Sinal SH, Hinds A. Dermatomyositis: a dermatology-based case series. J Am Acad Dermatol. 1998;38:397-404.

13. Scola RH, Werneck LC, Prevedello DM, Toderke EL, Iwamoto FM. Diagnosis of dermatomyositis and polymyositis. A study of 102 cases. Arq Neuropsiquiatr. 2000;58:789-99.

14. Mahil S, Marks D, McCormack M, Rahman A. Dermatomyositis. Br J Hosp. (Lond) 2012:73:C18-22.

15. Na SJ, Kim SM, Sunwoo IN, Choi YC. Clinical characteristics and outcomes of juvenile and adult dermatomyositis. J Korean Med Sci. 2009;24:715-21. 
16. Schiopu E, Phillips K, MacDonald PM, Crofford LJ, Somers EC. Predictors of survival in a cohort of patients with polymyositis and dermatomyositis: effect of corticoids, methotrexate and azathioprine. Arthritis Res Ther. 2012;14:R22.

17. Yosipovitch G, Tan A, LoSicco K, Manabat CG, Kannagra A, Carroll C, et al. A comparative study of clinical characteristics, work-up, treatment, and association to malignancy in dermatomyositis between two tertiary skin centers in the USA and Singapore. Int J Dermatol. 2013:52:813-9.

18. Adams-Gandhi LB, Boyd AS, King LE Jr. Diagnosis and management of dermatomyositis. Compr Ther. 1996;22:156-64.

19. Pellissier JF, Civatte M, Fernandez C, Bartoli C, Chetaille B, Schleinitz N, et al. Dermatomyositis and polymyositis. Rev Neurol (Paris). 2002;158:934-47.

20. Benbassat J, Gefel D, Larholt K, Sukenik S, Morgenstern V, Zlotnick A. Prognostic factors in polymyositis/dermatomyositis. A computer-assisted analysis of ninety-two cases. Arthritis Rheum. 1985;28:249-55

21. Parodi A, Caproni M, Marzano AV, De Simone C, La Placa M, Quaglino P, et al. Dermatomyositis in 132 patients with different clinical subtypes: cutaneous signs, constitutional symptoms and circulating antibodies. Acta Derm Venereol. 2002;82:48-51.

22. See $\mathrm{Y}$, Giam $\mathrm{YC}$, Chung HH. A retrospective study of 13 oriental children with juvenile dermatomyositis. Ann Acad Med Singapore. 1997;26:210-4.

23. Pachman LM, Hayford JR, Chung A, Daugherty CA, Pallansch MA, Fink CW, et al. Juvenile dermatomyositis at diagnosis: clinical characteristics of 79 children. J Rheumatol. 1998;25:1198-204.

24. Sallazar-Paramo M, Gonzáles-Covarrubias I, Garcia-De La Torre I. Características clínicas e sorológicas em um grupo de pacientes mexicanos com dermatomiosite juvenil. Rev Bras Reumatol. 1998;38:5-8.

25. Peloro TM, Miller OF 3rd, Hahn TF, Newman ED. Juvenile dermatomyositis: a retrospective review of a 30-year experience. J Am Acad Dermatol. 2001;45:28-34.

26. Jäger C, Sirvent N, Rabasse N, Soler C, Sebag F, Boutte P, et al. Juvenile dermatomyositis in the Nice area: a retrospective study 1991-2001. Ann Dermatol Venereol. 2002;129:1120-4.

27. Sallum AM, Kiss MH, Sachetti S, Resende MB, Moutinho KC, Carvalho Mde S, et al. Juvenile dermatomyositis: clinical, laboratorial, histological, therapeutical and evolutive parameters of 35 patients. Arq Neuropsiquiatr. 2002:60:889-99.

28. Mendez EP, Lipton R, Ramsey-Goldman R, Roettcher P, Bowyer S, Dyer A, et al. US incidence of juvenile dermatomyositis, 1995-1998: results from the National Institute of Arthritis and Musculoskeletal and Skin Diseases Registry. Arthritis Rheum. 2003;49:300-5.

29. Chowdhary V, Wakhlu A, Agarwal A, Misra R. Outcome in juvenile dermatomyositis. Indian Pediatr. 2002;39:931-5.

30. el-Azhary RA, Pakzad SY. Amyopathic dermatomyositis: retrospective review of 37 cases. J Am Acad Dermatol. 2002:46:560-5

31. Caproni M, Cardinali C, Parodi A, Giomi B, Papini M, Vaccaro M, et al. Amyopathic dermatomyositis. A review by the Italian group of immunodermatology. Arch Dermatol. 2002;138:23-7.

32. Cosnes A, Amaudric F, Gherardi R, Verroust J, Wechsler J, Revuz J, et al. Dermatomyositis without muscle weakness. Long-term follow-up of 12 patients without systemic corticosteroids. Arch Dermatol. 1995;131:1381-5.

33. Trüeb RM. Dermatomyositis. Dermatol Ther. 2001;14:70-80.

34. Naschitz JE, Rosner I, Rozenbaum M, Zuckerman E, Yeshurun D. Rheumatic syndromes: clues to occult neoplasia. Semin Arthritis Rheum. 1999;29:43-55.

35. Yazici Y, Kagen LJ. The association of malignancy with myositis. Curr Opin Rheumatol. 2000;12:498-500.

36. Hill CL, Zhang Y, Sigurgeirsson B, Pukkala E, Mellemkjaer L, Airio A, et al. Frequency of specific cancer types in dermatomyositis and polymyositis: a population-based study. Lancet. 2001;357:96-100.

37. Jorizzo JL, Carroll CL, Sangueza OP. Dermatomyositis. In: Bologna J, Jorizzo JL, Rapini RP, editors. Dermatology. 2nd ed. London: Mosby; 2008. v.1, p.575-83.

38. Buchbinder R, Forbes A, Hall S, Dennett X, Giles G. Incidence of malignant disease in biopsyproven inflammatory myopathy. A population-based cohort study. Ann Intern Med. 2001;134:1087-95

39. Pollak DF. Estudo da evoluçãa e prognóstico na dermatopolimiosite. Rev Bras Reumatol. 1986; 26:44-60.

40. Gallais V, Crickx B, Belaich S. Prognostic factors and predictive signs of malignancy in adult dermatomyositis. Ann Dermatol Venereol. 1996;123:722-6.

41. Maoz CR, Langevitz P, Livneh A, Blumstein Z, Sadeh M, Bank I, et al. High incidence of malignancies in patients with dermatomyositis and polymyositis: an 11-year analysis. Semin Arthritis Rheum. 1998;27:319-24.

42. Dourmishev LA. Dermatomyositis associated with malignancy. 12 case reports. Adv Exp Med Biol. 1999;455:193-9.

43. Chen YJ, Wu CY, Shen JL. Predicting factors of malignancy in dermatomyositis and polymyositis: a case-control study. Br J Dermatol. 2001;144:825-31.

44. Stockton D, Doherty VR, Brewster DH. Risk of cancer in patients with dermatomyositis or polymyositis, and follow-up implications: a Scottish population-based cohort study. $\mathrm{Br} \mathrm{J}$ Cancer. 2001;85:41-5.
45. Sparsa A, Liozon E, Herrmann F, Ly K, Lebrun V, Soria P, et al. Routine vs extensive malignancy search for adult dermatomyositis and polymyositis: a study of 40 patients. Arch Dermatol. 2002;138:885-90.

46. Pinto LF, Angel AM, Bohorquez R, Lopez CM. Caracterizacion de los pacientes con polimiositis y dermatomiositis del Servicio de Reumatologia de Instituto de Seguros Sociales de Medellín, Colombia, 1992-2000. Rev Colomb Reumatol. 2003;10:9-18.

47. Mebazâa A, Boussen H, Nouira R, Rokbani L, Ben Osman-Dhahri A, Bouaouina N, et al. Dermatomyositis and malignancy in Tunisia: A multicenter national retrospective study of 20 cases. J Am Acad Dermatol. 2003;48:530-4.

48. Basset-Seguin N, Roujeau JC, Gherardi R, Guillaume JC, Revuz J, Touraine R. Prognostic factors and predictive signs of malignancy in adult dermatomyositis. A study of 32 cases. Arch Dermatol. 1990;126:633-7.

49. Wakata N, Kurihara T, Saito E, Kinoshita M. Polymyositis and dermatomyositis associated with malignancy: a 30-year retrospective study. Int J Dermatol. 2002:41:729-34.

50. Wong KO. Dermatomyositis: a clinical investigation of twenty-three cases in Hong-Kong. $\mathrm{Br} J$ Dermatol. 1969:81:544-7.

51. Marie I, Hatron PY, Levesque H, Hachulla E, Hellot MF, Michon-Pasturel U, et al. Influence of age on characteristics of polymyositis and dermatomyositis in adults. Medicine (Baltimore). 1999;78:139-47.

52. Pautas E, Chérin P, Piette JC, Pelletier S, Wechsler B, Cabane J, et al. Features of polymyositis and dermatomyositis in the elderly: a case-control study. Clin Exp Rheumatol. 2000;18:241-4.

53. Hu WJ, Chen DL, Min HQ. Study of 45 cases of nasopharyngeal carcinoma with dermatomyositis. Am J Clin Oncol. 1996:19:35-8.

54. Leow YH, Goh CL. Malignancy in adult dermatomyositis. Int J Dermatol. 1997;36:904-7.

55. Chan HL. Dermatomyositis and cancer: East and West. J Am Acad Dermatol. 2000;42:699-700.

56. Hochberg MC, Feldman D, Stevens MB. Adult polymyositis/dermatomyositis: an analysis of clinical and laboratory features and survival in 76 patients with a review of the literature. Semin Arthritis Rheum. 1986;15:168-78.

57. Douglas WW, Tazelaar HD, Hartman TE, Hartman RP, Decker PA, Schroeder DR, et al. Polymyositis-dermatomyositis-associated interstitial lung disease. Am J Respir Crit Care Med. 2001;164:1182-5

58. Schnabel A, Reuter M, Biederer J, Richter C, Gross WL. Interstitial lung disease in polymyositis and dermatomyositis: clinical course and response to treatment. Semin Arthritis Rheum. 2003:32:273-84.

59. Weitoft T. Occurrence of polymyositis in the county of Gälleborg, Sweden. Scand J Rheumatol. 1997:26:104-6.

60. Kovacs SO, Kovacs SC. Dermatomyositis. J Am Acad Dermatol. 1998;39:899-920.

61. Marie I, Hachulla E, Hatron PY, Hellot MF, Levesque H, Devulder B, et al. Polymyositis and dermatomyositis: short term and longterm outcome, and predictive factors of prognosis. J Rheumatol. 2001:28:2230-7.

62. Jorizzo JL. Dermatomyositis. Practical Aspects. Arch Dermatol. 2002;138:114-6.

How to cite this article: Ortigosa LCM, Reis VMS. Dermatomyositis: analysis of 109 patients surveyed at the Hospital das Clínicas (HCFMUSP), São Paulo, Brazil. An Bras Dermatol. 2014;89(5):719-27. 